\title{
MORPHOMETRIC STUDY OF DRY HUMAN SCAPULAE
}

\author{
Susan Varghese1, Manju Madhavan Chandramathi Amma²
}

${ }^{1}$ Associate Professor, Department of Anatomy, Government T. D. Medical College, Alappuzha.

${ }^{2}$ Associate Professor, Department of Anatomy, Government Medical College, Thiruvananthapuram.

\section{ABSTRACT}

\section{BACKGROUND}

Variations of acromion has been associated with subacromial impingement syndrome and rotator cuff tear. Change in shape of glenoid cavity is important clinically, especially for shoulder arthroplasty. Variations in suprascapular notch with or without an anomalous superior transverse scapular ligament is a cause for suprascapular nerve entrapment syndrome.

\section{MATERIALS AND METHODS}

The total length, breadth and infraspinatus length of scapula along with scapular index and infraspinatus index, the shape, length, breadth and thickness of acromion process, acromiocoracoid distance, acromioglenoid distance, length, breadth and shape of glenoid cavity, and type of suprascapular notch, of 50 dry scapulae were studied.

\section{RESULTS}

Mean scapular index of $67.72 \mathrm{~mm}$ with SD of 3.72 and 70.01 with SD of 4.09 was observed in left and right scapulae respectively. A mean acromial breadth of $24.86 \mathrm{~mm}$ with SD of 2.88 and $27.36 \mathrm{~mm}$ with SD of 3.81 was noted. Acromial thickness showed a mean of $6.52 \mathrm{~mm}$ with SD 1.22 and $7.52 \mathrm{~mm}$ with SD 1.77 on left and right scapulae. Glenoid cavity lengths were $34.92 \mathrm{~mm}$ with SD of 2.14 and $36.92 \mathrm{~mm}$ with SD of 1.81 on the left and right scapulae respectively.

\section{CONCLUSION}

Scapular indices, acromial breadth, acromial thickness and glenoid cavity length were significantly higher on the right scapulae of the study group when compared to the left. Type II and type III suprascapular notches were predominantly seen with absence of notches in $12 \%$ and $16 \%$ in left and right scapula respectively. Morphometric variations are essential for clinicians to make proper diagnosis and most suitable surgical interventions.

\section{KEYWORDS}

Scapula, Morphometry, Acromion Process, Glenoid Cavity, Suprascapular Notch, Scapular Index.

HOW TO CITE THIS ARTICLE: Varghese S, Amma MMC. Morphometric study of dry human scapulae. J. Evolution Med. Dent. Sci. 2017;6(75):5365-5371, DOI: 10.14260/Jemds/2017/1164

\section{BACKGROUND}

Scapula forms an important component of the shoulder girdle. The triangular shape of the scapula is a characteristic feature of mammals and is not due to forces applied during development. Scapular shape has undergone modifications which can be expressed as scapular index indicating relationship of length to breadth of the bone. Shape change is mostly in the infraspinatus portion.

Acromion process of scapula has been classified by many researchers into three types. Type 1 flat; type 2 curved; type 3 hooked. Variations of acromion has been associated with sub acromial impingement syndrome and rotator cuff tear. or without an anomalous superior transverse scapular ligament is a cause for suprascapular nerve entrapment syndrome.

Determination of sex using scapular measurements is very useful in medicolegal cases, natural disasters and in circumstances where other bones are fragmented or not available.

Scapular measurements can be used for comparative anatomy, for surgical procedures and for manufacturing prosthetics. The dimensions of scapula are important in the case of rotator cuff diseases, shoulder arthroplasty and in recurrent shoulder dislocation.
\end{abstract} Glenoid cavity is considered as the head of the scapula. Different shapes of the glenoid cavity have been described; pear shaped, round, oval or inverted comma shaped. Variations in shape is important clinically, especially for shoulder arthroplasty. Variations in suprascapular notch with

Financial or Other, Competing Interest: None.

Submission 07-08-2017, Peer Review 05-09-2017,

Acceptance 11-09-2017, Published 18-09-2017.

Corresponding Author:

Dr. Manju Madhavan Chandramathi Amma,

Kadukkara Veedu, T.C. 16/4040,

Koyikkal Lane, Kumarapuram,

Medical College PO,

Thiruvananthapuram.

E-mail: manjumadhavanmch@gmail.com

DOI: $10.14260 /$ jemds $/ 2017 / 1164$

\section{MATERIALS AND METHODS}

Fifty adult dry human scapulae were included in the study of which 25 were of the left side and 25 of the right. The study was conducted in Government T D Medical college Alappuzha, Kerala.

\section{Study Design}

Descriptive study.

The Parameters Related to Scapula as a whole, Acromion Process and Glenoid Cavity were Measured using Vernier Callipers. They were-

- Length of scapula in $\mathrm{mm}$ is taken as the distance between the summit of the superior angle and the inferior angle. 
- Scapular breadth is the distance between the spine intersecting the medial border of scapula and the middle of outer border of glenoid cavity.

- Infraspinatus length is the distance between the point of intersection of spine of scapula to medial border and tip of inferior angle.

- Scapular index and infraspinatus index were measured using the above readings as follows.

Scapular index = breadth/length $\mathrm{x} 100$.

Infraspinatus index $=$ breadth/infraspinatus length $\mathrm{x}$ 100.

- Length of acromion process in $\mathrm{mm}$ is the distance between the tip and the posterior border of acromion process.

- Breadth of acromion process is the distance between the medial and lateral borders at the midpoint of acromion process.

- Thickness of acromion process was measured at the anterior part.

- The acromiocoracoid distance is the distance between the tip of acromion process and tip of coracoid process (fig. 7C).

- The acromioglenoid distance is the space between tip of acromion process and the supraglenoid tubercle (fig. 7B).

- Length of glenoid cavity (superior-inferior glenoid diameter): maximum distance between most inferior point on glenoid margin to supraglenoid tubercle.

- Breadth of glenoid cavity 1 (anteroposterior glenoid diameter 1): maximum breadth of articular margin of glenoid cavity perpendicular to glenoid cavity length (fig. 7A).

- Breadth of glenoid cavity 2 (anteroposterior glenoid diameter 2): breadth of upper half of glenoid cavity at the midpoint between superior margin and middle of glenoid cavity (fig. 7A).

- Shapes of acromion process and glenoid cavity were observed.

- $\quad$ Suprascapular notch types were observed and classified according to the classification by Polguj et al.

\section{Type I}

Notch with longer maximum depth (MD) than transverse diameter (fig. 8).

\section{Type II}

Equal depth and superior transverse diameter (STD) and mid transverse diameter (MTD) (fig. 9).

\section{Type III}

Longer superior transverse diameter than mid transverse diameter (fig. 10).

\section{Type IV}

Bony foramen (fig. 11).

\section{Type V}

Discrete notch (fig. 12).

Suprascapular notches may be absent (fig. 13).

\section{Statistical Analysis}

All measurements of left and right scapulae were made and tabulated. Mean and standard deviation were calculated manually.
In order to test whether the various parameters of left and right scapulae were different significantly, the equality of measure was tested using a small sample test, student ' $\mathrm{t}$ ' test, for unpaired independent samples. Values of $t$ was computed using an online calculator, the URL of which is www.socscistatistics.com/

\section{Figures Showing Measurements of Scapula}

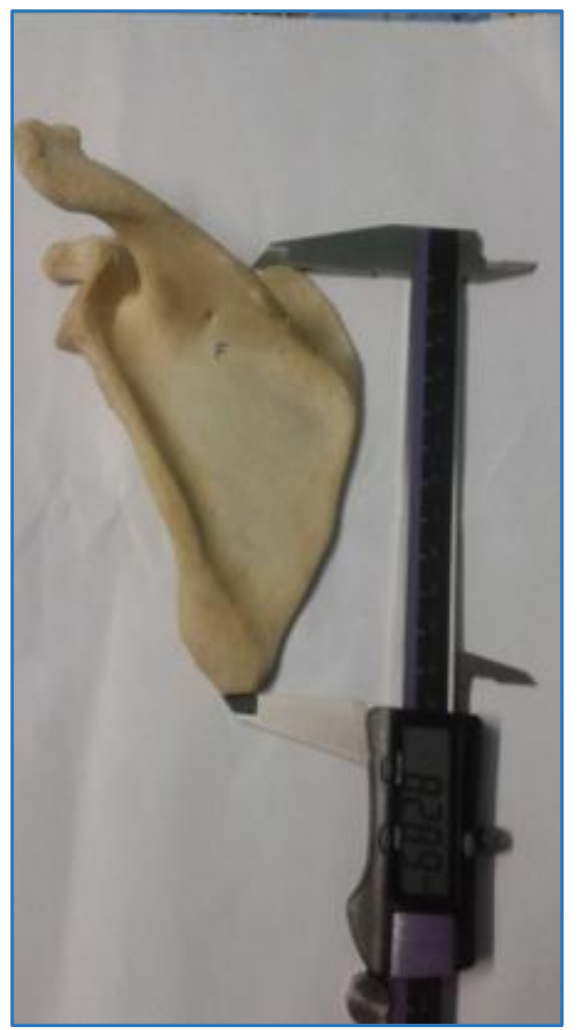

Figure 1. Scapular Length

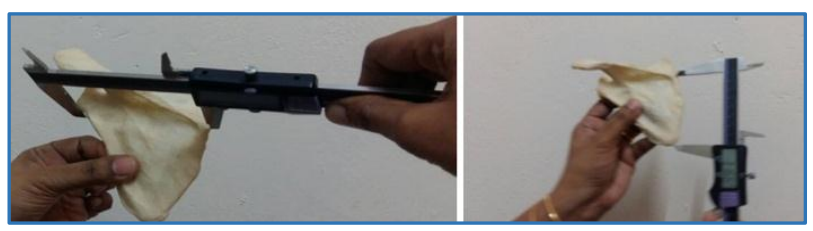

Figure 2. Scapular Breadth Figure 3. Infraspinatus Length

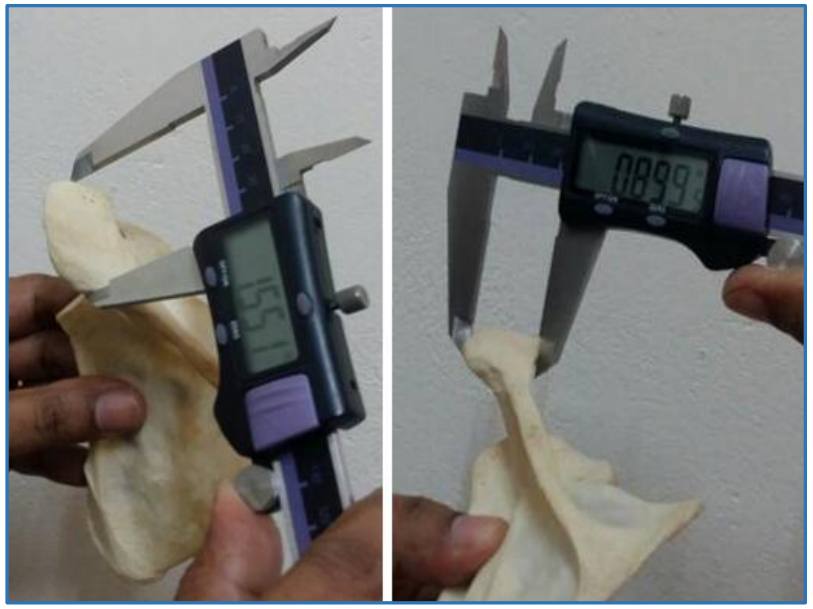

Figure 4. Acromial Length

Figure 5. Acromial Breadth 


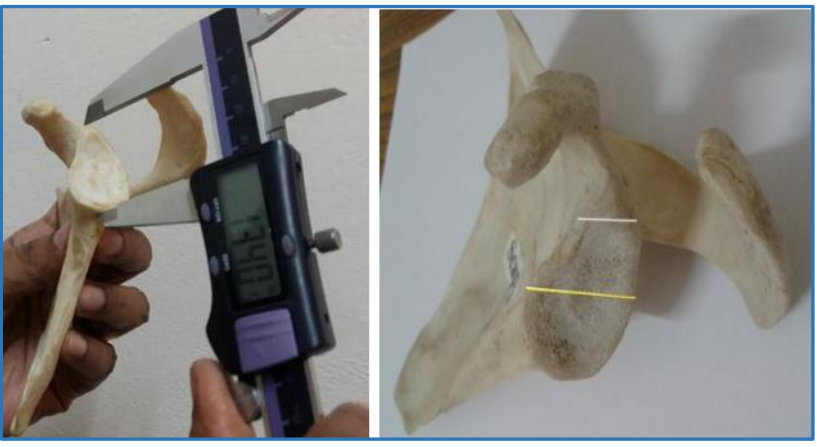

Figure 6. Glenoid Length

Figure 7A. Glenoid Cavity Breadth 1 \& 2

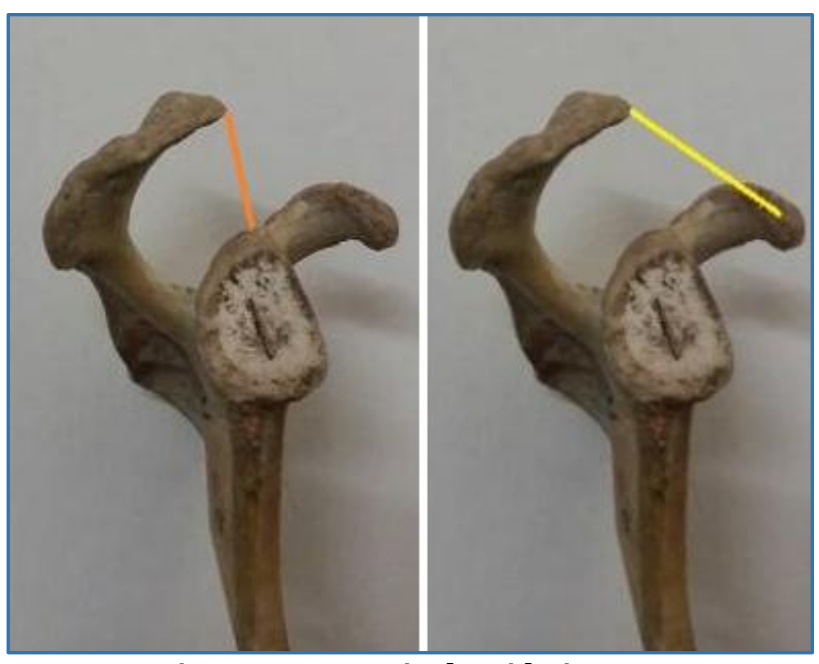

Figure 7B. Acromioglenoid Distance

Figure 7C. Acromiocoracoid Distance

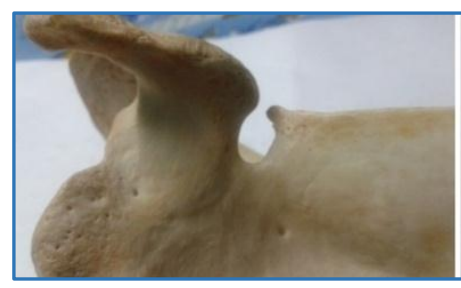

Figure 8. Type I

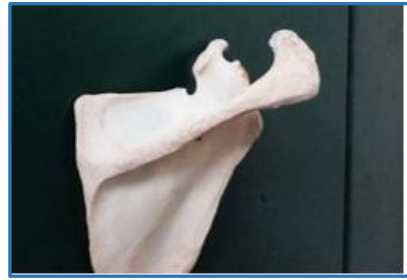

Figure 10. Type III

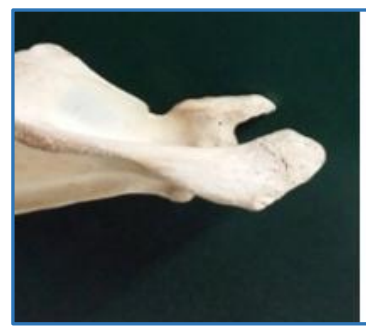

Figure 12. Type V

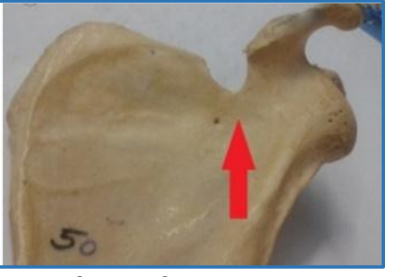

Figure 9. Type II

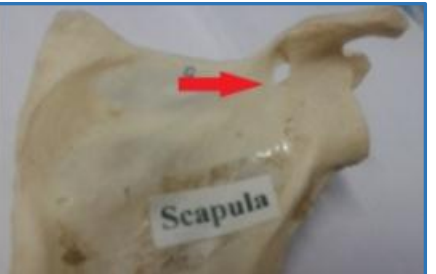

Figure 11. Type IV

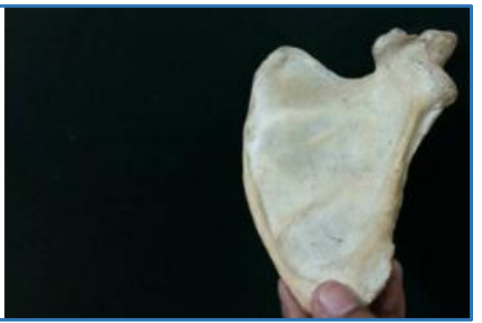

Figure 13. Absent Notch
RESULTS

\begin{tabular}{|c|c|c|}
\hline Parameter & Left & Right \\
\hline Number & 25 & 25 \\
\hline Range & $110.3-148.3 \mathrm{~mm}$ & $105-149.9 \mathrm{~mm}$ \\
\hline Mean & $130.38 \mathrm{~mm}$ & $130.11 \mathrm{~mm}$ \\
\hline S.D. & 11.05 & 10.96 \\
\hline \multicolumn{3}{|c|}{ Table 1. Total Length of Scapula } \\
\hline
\end{tabular}

The total length of scapula in the present study ranged from $110.3 \mathrm{~mm}$ to $148.3 \mathrm{~mm}$ on the left side and 105 to 149.9 $\mathrm{mm}$ on the right (table 1 ) with mean value of 130.8 \& 130.11 and standard deviation of $11.05 \& 10.96$ respectively, which was statistically insignificant $(t=0.7, p=0.4)$

\begin{tabular}{|c|c|c|}
\hline Parameter & Left & Right \\
\hline Number & 25 & 25 \\
\hline Range & $73-113 \mathrm{~mm}$ & $77.4-101.3 \mathrm{~mm}$ \\
\hline Mean & $89.68 \mathrm{~mm}$ & $90.0 \mathrm{~mm}$ \\
\hline S.D. & 8.88 & 6.20 \\
\hline \multicolumn{2}{|c|}{ Table 2. Breadth of Scapula } \\
\hline
\end{tabular}

Increased breadth was seen on right scapulae compared to those on the left as shown in table 2 but was insignificant statistically $(t=0.45, p=0.32)$.

\begin{tabular}{|c|c|c|}
\hline Parameter & Left & Right \\
\hline Number & 25 & 25 \\
\hline Range & $81-123.4 \mathrm{~mm}$ & $84.2-113.8 \mathrm{~mm}$ \\
\hline Mean & $98.54 \mathrm{~mm}$ & $99.32 \mathrm{~mm}$ \\
\hline S.D. & 10.41 & 8.02 \\
\hline \multicolumn{2}{|c|}{ Table 3. Infraspinatus Length } \\
\hline
\end{tabular}

Infraspinatus length more on right scapulae in comparison to left scapulae (table 3$).(t=0.29, p$ value $=0.38$. $\mathrm{p}>0.05$ ).

\begin{tabular}{|c|c|c|}
\hline Parameter & Left & Right \\
\hline Number & 25 & 25 \\
\hline Range & $61-76.8$ & $62.9-82.9$ \\
\hline Mean & 67.72 & 70.01 \\
\hline S.D. & 3.72 & 4.09 \\
\hline \multicolumn{2}{|c|}{ Table 4. Scapular Index } \\
\hline
\end{tabular}

Higher scapular index was noticed in right scapulae (table 4$)$ and shows statistical significance. $(\mathrm{t}=-2.02$, $\mathrm{p}$ value $=0.024), \mathrm{p}<0.05$.

\begin{tabular}{|c|c|c|}
\hline Parameter & Left & Right \\
\hline Number & 25 & 25 \\
\hline Range & $81.3-103.6$ & $82.1-105$ \\
\hline Mean & 90.93 & 91.90 \\
\hline S.D. & 4.96 & 5.48 \\
\hline \multicolumn{2}{|c|}{ Table 5. Infraspinatus Index } \\
\hline
\end{tabular}

Correlation between breadth and infraspinatus length of scapula (infraspinatus index) was in the range of 81.3 -103.6 on the left and 82.1 - 105 on the right (table 5) and was not significant statistically $(\mathrm{t}=-0.643, \mathrm{p}$ value $=0.26)$. 


\begin{tabular}{|c|c|c|}
\hline Parameter & Left & Right \\
\hline Number & 25 & 25 \\
\hline Range & $33.4-51 \mathrm{~mm}$ & $31.6-48.2 \mathrm{~mm}$ \\
\hline Mean & $42 \mathrm{~mm}$ & $42.11 \mathrm{~mm}$ \\
\hline S.D. & 5.23 & 4.14 \\
\hline \multicolumn{2}{|c|}{ Table 6. Length of Acromion Process } \\
\hline
\end{tabular}

Left scapulae showed longer acromion processes than right ones (table 6) but was not significant statistically. $(\mathrm{t}=-0.114, \mathrm{p}$ value $=0.45)$.

\begin{tabular}{|c|c|c|}
\hline Parameter & Left & Right \\
\hline Number & 25 & 25 \\
\hline Range & $19-30.4 \mathrm{~mm}$ & $20.5-34.8 \mathrm{~mm}$ \\
\hline Mean & $24.86 \mathrm{~mm}$ & $27.36 \mathrm{~mm}$ \\
\hline S.D. & 2.88 & 3.81 \\
\hline \multicolumn{2}{|c|}{ Table 7. Breadth of Acromion Process } \\
\hline
\end{tabular}

Broader acromion processes were seen on right scapulae with mean value of 24.86 on the left and 27.36 on the right side and is statistically significant $(t=-2.763$, $p$ value $=0.004)$ $\mathrm{p}<0.05$ as seen in table 7 .

\begin{tabular}{|c|c|c|}
\hline Parameter & Left & Right \\
\hline Number & 25 & 25 \\
\hline Range & $4.5-9.1 \mathrm{~mm}$ & $4.2-10.3 \mathrm{~mm}$ \\
\hline Mean & $6.52 \mathrm{~mm}$ & $7.52 \mathrm{~mm}$ \\
\hline S.D. & 1.22 & 1.77 \\
\hline \multicolumn{2}{|c|}{ Table 8. Acromion Thickness } \\
\hline
\end{tabular}

Thickness of acromion process was higher on the right scapulae with mean values of 6.52 and SD 1.22 on left and 7.52 and SD 1.77 on right (table 8) which is significant statistically. $(\mathrm{t}=-2.15$, $\mathrm{p}$ value $=0.017)$.

\begin{tabular}{|c|c|c|}
\hline Parameter & Left & Right \\
\hline Number & 25 & 25 \\
\hline Range & $18.2-41.2 \mathrm{~mm}$ & $18-31.8 \mathrm{~mm}$ \\
\hline Mean & $26.02 \mathrm{~mm}$ & $26.67 \mathrm{~mm}$ \\
\hline S.D. & 5 & 4.15 \\
\hline T $=-0.47$ & & \\
\hline \multicolumn{2}{|c|}{ Table 9. Acromiocoracoid Distance } \\
\hline
\end{tabular}

Acromiocoracoid distance was not significantly different on both scapulae $(\mathrm{t}=0.31, \mathrm{p}=0.37)$ as shown in table 9 .

\begin{tabular}{|c|c|c|}
\hline Parameter & Left & Right \\
\hline Number & 25 & 25 \\
\hline Range & $14-26.2 \mathrm{~mm}$ & $13.6-22 \mathrm{~mm}$ \\
\hline Mean & $18.87 \mathrm{~mm}$ & $18.10 \mathrm{~mm}$ \\
\hline S.D. & 2.77 & 2.74 \\
\hline \multicolumn{2}{|c|}{ Table 10. Acromioglenoid Distance } \\
\hline
\end{tabular}

$(\mathrm{t}=0.99 . \mathrm{p}$ value $=0.16)$.

Acromioglenoid distance of both sides did not differ significantly (table 10).

\begin{tabular}{|c|c|c|}
\hline Parameter & Left & Right \\
\hline Number & 25 & 25 \\
\hline Range & $32-40.6 \mathrm{~mm}$ & $30-42.9 \mathrm{~mm}$ \\
\hline Mean & $34.92 \mathrm{~mm}$ & $36.92 \mathrm{~mm}$ \\
\hline S.D. & 2.14 & 1.81 \\
\hline \multicolumn{2}{|c|}{ Table 11. Length of Glenoid Cavity } \\
\hline
\end{tabular}

$(\mathrm{t}=-2.210, \mathrm{p}$ value $=0.015) \mathrm{p}<0.05$.

Table 11 shows statistically significant increase of glenoid cavity length on right scapulae with mean value of 34.92 and SD 2.14 on the left and mean value 36.92 and SD 1.81 on the right.

\begin{tabular}{|c|c|c|}
\hline Parameter & Left & Right \\
\hline Number & 25 & 25 \\
\hline Range & $19-25.3 \mathrm{~mm}$ & $18.2-29 \mathrm{~mm}$ \\
\hline Mean & $22.19 \mathrm{~mm}$ & $23.91 \mathrm{~mm}$ \\
\hline S.D. & 1.52 & 2.91 \\
\hline \multicolumn{2}{|c|}{ Table 12. Glenoid Cavity Breadth 1 } \\
\hline
\end{tabular}

$(\mathrm{t}=-1.32, \mathrm{p}$ value $=0.095)$

Table 12 shows no significant difference of glenoid cavity breadth in the upper part.

\begin{tabular}{|c|c|c|}
\hline Parameter & Left & Right \\
\hline Number & 25 & 25 \\
\hline Range & $11.4-21.8 \mathrm{~mm}$ & $11.7-21.3 \mathrm{~mm}$ \\
\hline Mean & $16.27 \mathrm{~mm}$ & $16.52 \mathrm{~mm}$ \\
\hline S.D. & 2.51 & 2.48 \\
\hline \multicolumn{2}{|c|}{ Table 13. Glenoid Cavity Breadth 2} \\
\hline
\end{tabular}

$(\mathrm{t}=-0.31, \mathrm{p}$ value $=0.37)$ No significant difference observed in maximum breadth of glenoid cavity (Table 13).

\begin{tabular}{|c|c|c|}
\hline Shape & Left & Right \\
\hline Pear & $(52 \%)$ & $(36 \%)$ \\
\hline Oval & $(20 \%)$ & $(24 \%)$ \\
\hline Inverted Comma & $(28 \%)$ & $(40 \%)$ \\
\hline \multicolumn{2}{|c|}{ Table 14. Shape and Frequency of Glenoid Cavity } \\
\hline
\end{tabular}

13 left scapulae had pear shaped, 5 had oval shaped \& 7 had inverted comma shaped glenoid cavity among the study group and 9 right scapulae showed pear shaped, 6 showed oval shaped and 10 showed inverted comma shaped glenoid cavity (table 14 \& chart 1 ).

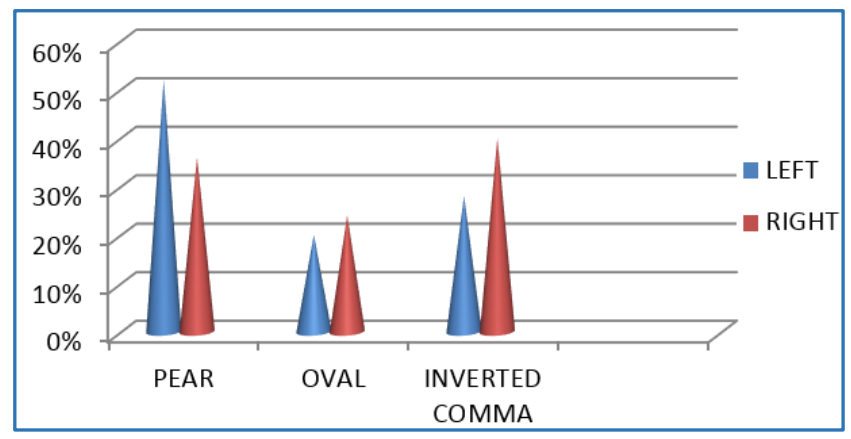

Chart 1. Shape of Glenoid Cavity 


\begin{tabular}{|c|c|c|}
\hline Shape & Left & Right \\
\hline Rectangular & $10(40 \%)$ & $14(56 \%)$ \\
\hline Tubular & $11(44 \%)$ & $7(28 \%)$ \\
\hline Triangular & $1(4 \%)$ & $1(4 \%)$ \\
\hline Curved & $3(12 \%)$ & $3(12 \%)$ \\
\hline Table 15. Shape and Frequency of Acromion Process \\
\hline
\end{tabular}

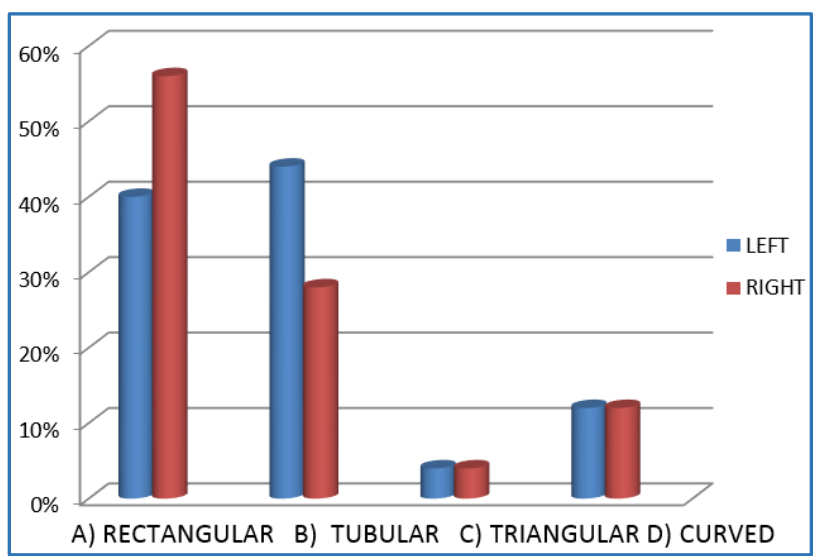

Chart 2. Shape of Acromion Processes

Table 15 and chart 2 shows distribution of acromion process shape among the study group.

\begin{tabular}{|c|c|c|}
\hline SSN & Left & Right \\
\hline Type I & $1(4 \%)$ & $4(16 \%)$ \\
\hline Type II & $9(36 \%)$ & $8(32 \%)$ \\
\hline Type III & $8(32 \%)$ & $8(32 \%)$ \\
\hline Type IV & $3(12 \%)$ & 0 \\
\hline Type V & $1(4 \%)$ & $1(4 \%)$ \\
\hline Absent & $3(12 \%)$ & $4(16 \%)$ \\
\hline \multicolumn{2}{|c|}{ Table 16. Frequency of Suprascapular Notch Types } \\
\hline
\end{tabular}

Type II suprascapular notches were more commonly seen on left scapulae whereas Types II \& III were equally seen and more common on right scapulae (Table 16 \& Chart 3).

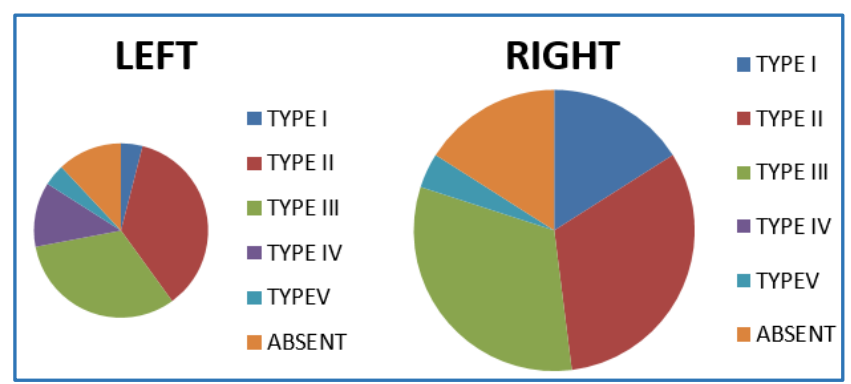

Chart 3. Types of Suprascapular Notches

\section{DISCUSSION}

Since the scapula varies in morphology, its measurements have importance in shoulder girdle pathologies. Each individual presents with variations in shoulder anatomy, overall conditioning and fitness and degrees of shoulder laxity that makes the precise evaluation of pathologic lesions difficult. ${ }^{1}$ The slope and length of the acromion and the height of the arch are most closely associated with degenerative changes. ${ }^{2}$

\section{Scapular Length}

Mean scapular length was $132.38 \mathrm{~mm}$ with standard deviation of 11.05 on left scapulae and $130.11 \mathrm{~mm}$ with SD of 10.96 on right scapulae in our study. Gupta ${ }^{3}$ et al reported mean scapular length of $135.3 \mathrm{~mm}$ with SD of 10.9 which is similar to our study. Maximum scapular height is the maximum distance between the highest point of the superior angle and the lowest point of the inferior angle. ${ }^{4}$

\section{Scapular Breadth}

Maximum scapular breadth is the maximum distance between the point on the longitudinal axis of the glenoid cavity and the point on the prolongation of the inferior boundary of the closed margin of the spine. The mean breadth of scapula was $89.68 \mathrm{~mm}$ with SD of 8.88 on left scapulae and $90.9 \mathrm{~mm}$ with SD of 6.20 in the present study which was in accordance with Gupta et al.

\section{Infraspinatus Length}

The change in shape of scapula is more common in infraspinatus region. The mean infraspinatus length was $98.54 \mathrm{~mm}$ with SD of 10.41 on left scapulae and $99.32 \mathrm{~mm}$ with SD of 8.02 on the right, while Krishnaiah ${ }^{5}$ et al reported a higher value of $107.71 \mathrm{~mm}$ with SD of 7.6.

\section{Scapular Index}

Scapular indices help in determining the race. The mean scapular index observed in our study was 67.72 with SD of 3.72 on the left and 70.01 with SD of 4.09 on the right scapulae which is less than those of Krishnaiah's study which showed 73.99 with SD of 4.6.

\section{Infraspinatus Index}

The present study showed a mean infraspinatus index of 90.93 with SD of 4.96 on left and 91.90 with SD of 5.48 on right scapulae.

\section{Length of Acromion Process}

Acromion process plays a significant role in formation and stability of shoulder joint. Our study showed a mean acromial length of $42 \mathrm{~mm}$ with SD of 5.23 on left and $42.11 \mathrm{~mm}$ with SD of 4.14 on right scapulae whereas Mansur' ${ }^{6}$ et al found mean length of $45.57 \mathrm{~mm}$ with SD of $5.1 \mathrm{on}$ left and $46.46 \mathrm{~mm}$ with SD of 5 on right acromion in Nepalese population.

\section{Breadth of Acromion}

The mean breadth of acromion in our scapulae were 24.86 mm with SD of 2.88 on the left and $27.36 \mathrm{~mm}$ with SD of 3.81 on right acromial processes, while Mansur et al found mean breadth of $27.23 \mathrm{~mm}$ with SD of 3.06 on left and $26.63 \mathrm{~mm}$ with SD of 3.55 on the right acromion processes, which is in accordance to our study.

\section{Acromial Thickness}

Acromial thickness showed a mean value of $6.52 \mathrm{~mm}$ with SD of 1.22 on the left and $7.52 \mathrm{~mm}$ with SD of 1.77 on the right indicating an increase on the right acromia.

\section{Shape of Acromion}

$44 \%$ of scapulae on left revealed tubular acromion processes whereas $56 \%$ were rectangular on the right. The second 
commonest was rectangular (40\%) on left and tubular (28\%) on the right. Acromion process was classified into three types on the basis of its shape into triangular, quadrangular, and tubular by Mansur et al. Curved acromia were also seen. The under surface of anterior one third of acromion was pointed out by $\mathrm{Neer}^{7}$ as the area responsible for impinging upon the components of the rotator cuff especially the supraspinatus tendon. Rotator cuff lesions are common where subacromial space is narrow.

\section{Acromiocoracoid Distance and Acromioglenoid Distance} No significant difference of these were noted between scapulae of both sides in the present study.

\section{Glenoid Cavity Length}

Height of the glenoid cavity is the maximum distance from inferior point of glenoid margin to the most prominent point on supraglenoid tubercle. Mean value of $34.92 \mathrm{~mm}$ with SD of 2.14 was noted on the left and $36.92 \mathrm{~mm}$ with SD of 1.81 on the right glenoids and the difference was highly significant and was similar to the study by Patil et al. The left glenoid cavities were slightly shorter in length in comparison to the right.

\section{Glenoid Cavity Breadth 1}

Glenoid cavity breadth is the maximum breadth of the articular margin, perpendicular to glenoid cavity height. The mean of maximum diameter of lower part of glenoid cavity was $22.19 \mathrm{~mm}$ with SD of 1.52 on the left and $23.91 \mathrm{~mm}$ with SD of 2.91 on the right.

\section{Glenoid Cavity Breadth 2}

The mean of diameter of upper part of glenoid cavity was $16.27 \mathrm{~mm}$ with SD of 2.51 on left and 16.52 with SD of 2.48 on the right glenoids and was in accordance with Patil ${ }^{8}$ et al. But Iannoti ${ }^{9}$ et al found a mean diameter of $23 \mathrm{~mm}$ with SD of 2.7 which is higher than that of our study.

\section{Shape of Glenoid Cavity}

The glenoid cavity has been classified into pear shaped, inverted comma or oval, based on the presence of a notch on the anterior glenoid rim, ${ }^{10}$ Pear-shaped glenoids were more frequently seen on left scapulae (52\%) and inverted comma shaped ones $(40 \%)$ on the right.

\section{Suprascapular Notch}

Suprascapular notch is a depression on the lateral part of superior border of scapula, medial to the coracoid process. It is bridged by superior transverse scapular ligament which may ossify and the foramen then transmits suprascapular nerve to supraspinatus fossa.11,12 Bony foramina were seen in $12 \%$ of left scapulae while none was found on the right. This notch is an important landmark of suprascapular nerve during arthroscopic shoulder surgery. ${ }^{13,14}$ Rengachary's ${ }^{15}$ classification of suprascapular notches says that in type 1 , the superior border of scapula present a depression from the medial superior angle to the base of coracoid process; type II is described as a wide blunted ' $V$ ' shaped notch, occupying nearly a third of the superior border with the widest point along the superior border. Type III is a symmetric and " $U$ " shaped notch while type IV is described as a very small " $\mathrm{V}$ " shaped notch frequently presenting a shallow groove near the notch; type $\mathrm{V}$ is similar to type III with partial ossification of medial border of the notch and with minimum diameter along superior border of scapula. Type VI is described as a bony foramen with a completely ossified superior transverse scapular ligament. In the present study, suprascapular notches were classified by Polguj's ${ }^{16}$ classification and type II was more common (36\%) on left scapulae than that on right (32\%) whereas type III showed equal distribution $32 \%$ each) on both sides. Suprascapular notch was absent in $12 \%$ on the left and $16 \%$ on the right.

In the whole population, approximately $1-2 \%$ of all shoulder pain is caused by suprascapular nerve impingement syndrome. ${ }^{17}$ According to Albino, ${ }^{18}$ suprascapular entrapment syndrome is more likely to be associated with type III notch because of its peculiar features.

\section{CONCLUSION}

Scapular index indicates the relationship of breadth to length of scapula and reveals modifications in shape of the bone and is useful to compare racial differences. Right scapulae of the study group showed higher indices than left scapulae.

Acromion thickness and acromial breadth were slightly more in right-sided scapulae. The different shapes and curvature of acromion has a role in impingement syndrome.

Glenoid cavity was longer on right scapulae in the present study and may be of significance to surgeons in shoulder arthroplasty.

Type II and type III Suprascapular notches were predominantly seen. Occurrence of a completely ossified superior transverse scapular ligament can have a genetic influence and can cause suprascapular nerve entrapment syndrome.

\section{REFERENCES}

[1] Warner JJ, Deng XH, Warren RF, et al. Static capsuloligamentous restraints to superior-inferior translation of the glenohumeral joint. Am J Sports Med 1992;20(6):675-85.

[2] Edelson JG, Taitz C. Anatomy of the coraco-acromial arch. Relation to degeneration of the acromion. J Bone Joint Surg Br 1992;74(4):589-94.

[3] Gupta C, Priya A, Kalthur SG, et al. A morphometric study of acromion process of scapula and its clinical significance. CHRISMED J Health Res 2014;1(3):164-9.

[4] Patel SM, Shah MA, Vora RK, et al. Morphometric analysis of scapula to determine sexual dimorphism. Int J Med Public Health 2013;3:207-10.

[5] Krishnaiah M, Nagaraj S, Kumar PM, et al. Study of scapular measurements and scapular indices of Andhra Pradesh region. IOSR Journal of Dental and Medical Sciences 2014;13(6):117-20.

[6] Mansur DI, Khanal K, Haque MK, et al. Morphometry of acromion process of human scapulae and its clinical importance amongst Nepalese population. Kathmandu Univ Med J 2012;38(2):33-6.

[7] Neer CS. Anterior acromioplasty for the chronic impingement syndrome in the shoulder: a preliminary report. J Bone Joint Surg Am 1972;54(1):41-50. 
[8] Patil GV, Kolagi SI, Ramdurg U. Morphometrical study of scapular glenoid cavities. Global Journal of Medical research 2014;14(2).

[9] Iannotti JP, Gabriel JP, Schneck SL, et al. The normal glenohumeral relationship. An anatomical study of one hundred and forty shoulders. Journal of Bone and Joint Surgery 1992;74(4):491-500.

[10] Prescher A, Klumpen T. The glenoid notch and its relation to the shape of the glenoid cavity of the scapula. Journal of Anatomy 1997;190(Pt 3):457-60.

[11] Ajmani ML. The cutaneous branch of the human suprascapular nerve. J Anat 1994;185(Pt 2):439-42.

[12] Standring S, Ellis H, Healy J, et al. Gray's anatomy-the anatomical basis of clinical practice. $39^{\text {th }}$ edn. New York, Elsevier Churchill Livingstone. Pectoral girdle, shoulder region and axilla 2005:821-2.

[13] Bigliani LU, Dalsey RM, McCann PD, et al. An anatomical study of the suprascapular nerve. Arthroscopy 1990;6(4):301-5.
[14] Shishido H, Kikuchi S. Injury to the suprascapular nerve during shoulder joint surgery: an anatomical study. J Shoulder Elbow Surg 2001;10(4):372-6.

[15] Rengachary SS, Neff JP, Singer PA, et al. Suprascapular entrapment neuropathy: a clinical, anatomical and comparative study. Part 1: clinical study. Neurosurgery 1979;5(4):441-6.

[16] Polguj M, Sibinsky M, Grzegorzewski A, et al. Variation in morphology of suprascapular nerve as a factor of suprascapular nerve entrapment. Int Orthop 2013;37(11):2185-92.

[17] Polguj M, Jolzejewski KS, Podgorski M, et al. Correlation between morphometry of the suprascapular notch and anthropometric measurements of the scapula. Folia Morphol 2011;70(2):109-15.

[18] Albino P, Carbone S, Candela V, et al. Morphometry of the suprascapular notch: correlation with scapular dimensions and clinical relevance. Biomed Central Musculoskeletal disorders 2013;14:172. 